\title{
New solution-processable carbazole derivatives as deep blue emitters for Organic Light-Emitting Diodes
}

\author{
Marta Reig, ${ }^{a}$ Giedre Bubniene, ${ }^{a}$ Werther Cambarau, ${ }^{b}$ Vygintas Jankauskas, ${ }^{c}$ Vytautas Getautis, ${ }^{d}$ \\ Emilio Palomares, ${ }^{b, e}$ Eugenia Martínez-Ferrero ${ }^{f}$ and Dolores Velasco ${ }^{* a}$

\begin{abstract}
Two new compounds based on three carbazole units connected by triple bonds as $\pi$-spacers have been developed as deep blue emitters for organic light-emitting diodes (OLEDs). Their optical and electrochemical properties were examined and the charge carrier transport properties were investigated by means of the xerographic time-of-flight (XTOF) technique. The prepared diodes demonstrate the feasibility of the new molecules as effective emitters in the deep blue region yielding devices with low turn-on voltages.
\end{abstract}

\section{Introduction}

Organic light-emitting diodes (OLEDs) have been studied extensively due to their promising applications in flat-panel displays and solid-state lighting. However, further improvement of power efficiency, colour purity and longer operational lifetimes are still required to produce efficient industrial devices. The development of OLEDs that emit in the blue region (defined by the Commission Internationale de l'Eclairage chromaticity y coordinate (CIEy) value less than 0.1 ) have attracted intensive research, since these materials can be applied in combination to green and red colour emitters in white OLEDs and full-colour displays. Whereas green and red emitters have reached a more successful development, the fabrication of high power-efficiency and bright blue OLEDs is complex due to the intrinsic large band gaps of the organic materials, which difficult the injection of charges into the emitters, and the lower sensitivity of the human eye in this part of the electromagnetic spectrum, which decreases the efficacy. In addition, blue OLEDs are more prone to degradation showing poor long-term stability and shorter lifetimes. ${ }^{1}$ Nevertheless, several efficient deep-blue OLEDs have been reported without the use of host-dopant systems. ${ }^{2}$

\footnotetext{
a. Grup de Materials Orgànics, Institut de Nanociència i Nanotecnologia (IN $\left.{ }^{2} U B\right)$, Departament de Química Orgànica, Universitat de Barcelona, Martí i Franquès 1 E-08028, Barcelona, Spain.E-mail: dvelasco@ub.edu; Fax: +34 93339 78 78; Tel: +34934039260

${ }^{b}$ Institute of Chemical Research of Catalonia (ICIQ), The Barcelona Institute of Science and Technology (BIST), Avda. Països Catalans, 16, E-43007, Tarragona, Spain.

Department of Solid State Electronics, Vilnius University, Sauletekio al. 9, Vilnius, LT-10222, Lithuania.

${ }^{d .}$ Department of Organic Chemistry, Kaunas University of Technology, Radvilenu pl. 19, Kaunas, LT-50254, Lithuania.

e. Catalan Institution for Research and Advance Studies (ICREA), Avda. Lluis Companys 23, E-08010 Barcelona, Spain.

f. Fundació Eurecat. Av. d'Ernest Lluch 36, Parc Científic i de la Innovació TecnoCampus, E-08302, Mataró, Barcelona, Spain.

† Footnotes relating to the title and/or authors should appear here.

Electronic Supplementary Information (ESI) available: ${ }^{1} \mathrm{H} N M R,{ }^{13} \mathrm{C}$ NMR and mass spectra, Cyclic voltammograms, XTOF characteristics, average values of OLED devices and digital picture of an OLED device. See DOI: 10.1039/x0xx00000x
}

Carbazole based compounds have been reported as good candidates for hole transport materials. ${ }^{3}$ In addition, the relatively weak $\pi$-donating ability of the carbazole moiety makes of them suitable candidates for deep-blue emitters. ${ }^{4}$ Therefore, the design of new carbazole based dyes that could present both blue fluorescent properties and hole transport characteristics is an attractive challenge. Herein we present the synthesis and physical properties of two new dyes, which incorporate three carbazole units in their design (Scheme 1). Whereas the central carbazole unit has been maintained with no substitution in the nitrogen atom to favour electronic delocalization, the two external carbazole units connected to the 3 and 6 positions of the central core have been substituted by two different groups to introduce steric hindrance in order to get higher quantum yields. The carbazole triple based substitution has been selected to promote luminescence in the blue zone of the visible spectrum. Furthermore, carbazole derivatives are soluble in many solvents, overcoming the insolubility of small molecules and opening the door to the construction of OLEDs by solution processing.

\section{Results and discussion}

\section{Synthesis and characterization}

Two new blue fluorescent carbazole-based dyes were designed and synthesized, as shown in Scheme 1. Sonogashira coupling reaction $^{5}$ of 3,6-diethynyl-9H-carbazole ${ }^{6}$ with $\mathbf{1}$ and $\mathbf{2}$ in the presence of triethylamine (TEA) under $\mathrm{Pd}\left(\mathrm{PPh}_{3}\right)_{2} \mathrm{Cl}_{2}$ catalysis gave final derivatives 3,6-bis[2-(9-(2-ethylhexyl)-9H-carbazol-3yl)ethynyl]-9H-carbazole (3a) and 3,6-bis[2-(9-(3,5-di-tertbutylphenyl)-9H-carbazol-3-yl)ethynyl]-9H-carbazole

(3b), respectively. Previously, compounds $\mathbf{1}^{7}$ and $\mathbf{2}$ were prepared from 3-iodo-9H-carbazole (MIC) ${ }^{8}$ with 2-ethylhexyl bromide in the presence of $\mathrm{KOH}$ and 1-bromo-3,5-di-tert-butylbenzene, respectively.

In order to get coupling product $\mathbf{3 b}$ in higher yield, a second synthetic route was investigated from 3,6-diiodo- $9 \mathrm{H}$ carbazole (DIC). ${ }^{8}$ For that purpose 9-(3,5-di-tert-butylphenyl)- 

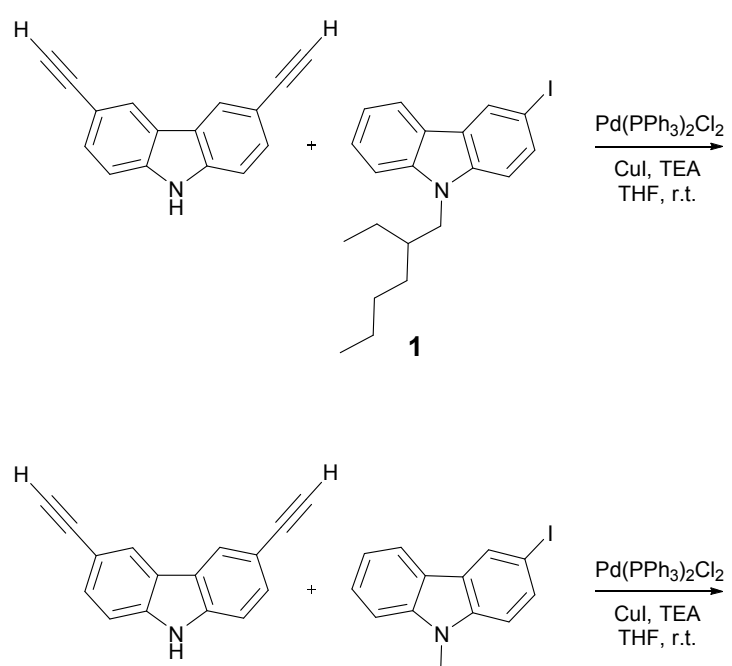<smiles>CC(C)(C)c1cc(-n2c3ccccc3c3cc(I)ccc32)cc(C(C)(C)C)c1</smiles>

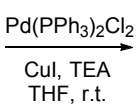

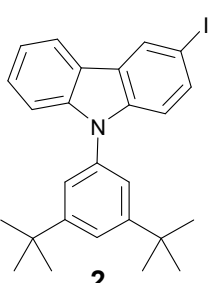

2
THF, r.t.
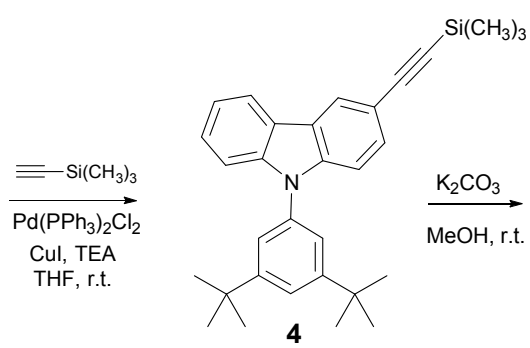

4

Scheme 1 Synthetic routes towards $\mathbf{3 a}$ and $\mathbf{3 b}$.
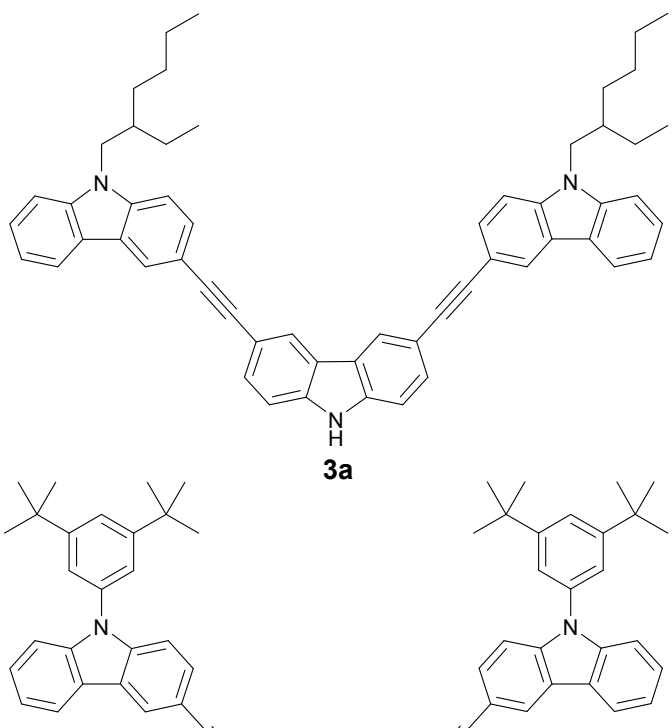<smiles>Cc1ccc2c(c1)c1ccccc1n2-c1cc(C(C)(C)C)cc(C(C)(C)C)c1</smiles>

$3 b$
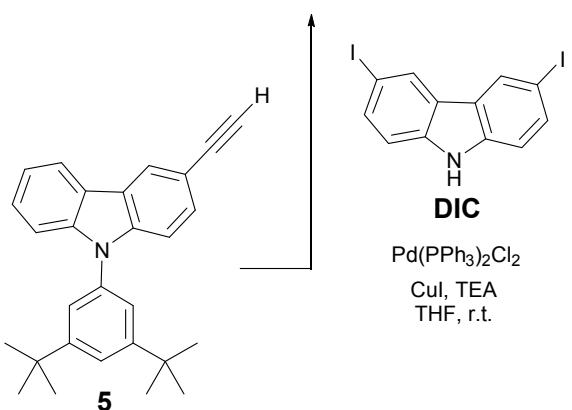

$\mathrm{Pd}\left(\mathrm{PPh}_{3}\right)_{2} \mathrm{Cl}_{2}$

Cul, TEA
THF, r.t.

(4) and 9-(3,5-di-

3-[2-(trimethylsilyl)ethynyl)]-9H-carbazole tert-butylphenyl)-3-ethynyl-9H-carbazole (5) were prepared from compound $\mathbf{2}$. The second route afforded a slight increase of the yield from 15 to $24 \%$.

The chemical structure of all synthesized compounds was confirmed by spectroscopy techniques $\left({ }^{1} \mathrm{H}\right.$ NMR and $\left.{ }^{13} \mathrm{C} N M R\right)$ and mass spectra.

\section{Photophysical properties}

Molecules $\mathbf{3} \mathbf{a}$ and $\mathbf{3} \mathbf{b}$ are soluble in common organic solvents such as chlorobenzene, dichloromethane or tetrahydrofuran. The photophysical properties of dyes $\mathbf{3 a}$ and $\mathbf{3} \mathbf{b}$ in solution and in solid state are summarized in Table 1. Fluorescence measurements in dichloromethane solution, after excitation at
$300 \mathrm{~nm}$, show maximum fluorescent peaks centred at 371 and 392, and at 369 and $390 \mathrm{~nm}$, for $\mathbf{3 a}$ and $\mathbf{3 b}$, respectively. The emission in solid state samples after photoexcitation renders a single peak in both cases located at 410 and $398 \mathrm{~nm}$, respectively (Fig. 1). The bathochromic shift observed in the solid state emission, compared to the measurements in solution, is more evident on the $\mathbf{3 a}$ molecule due to the lower steric hindrance, in comparison to compound $\mathbf{3 b}$ with the 3,5di-tert-butylphenyl group, allowing better van der Waals interactions between neighbouring molecules. The quantum yield of the $\mathrm{N}$-aryl substituted $\mathbf{3 b}$ solid state thin-films drops from 0.31 in solution to 0.11 in the solid state, while the $\mathrm{N}$ alkylated analogue 3a maintain substantially unchanged its fluorescence efficiency. Therefore, the introduction of the 2ethylhexyl substitution on the carbazole units has

Table 1 Optical and electrochemical properties for compounds $\mathbf{3 a}$ and $\mathbf{3 b}$.

\begin{tabular}{|c|c|c|c|c|c|c|c|c|c|c|}
\hline compd. & $\lambda_{\text {abs, } \max }(n m)^{a}$ & $\lambda_{\mathrm{em}, \max }(\mathrm{nm})^{\mathrm{a}}$ & $\Phi^{a}$ & $\lambda_{\mathrm{em}, \max }(\mathrm{nm})^{\mathrm{b}}$ & $\Phi^{b}$ & $\mathrm{CIE}^{\mathrm{b}}$ & $E_{\text {gap }}(\mathrm{eV})^{\mathrm{c}}$ & $E_{\text {onset }}{ }^{\text {ox }}(\mathrm{V})^{\mathrm{d}}$ & IP $(e V)^{e}$ & EA $(e V)$ \\
\hline $3 a$ & $305,325,349$ & 371,392 & 0.39 & 410 & 0.31 & $(0.17,0.07)$ & 3.32 & 0.93 & 5.89 & 2.57 \\
\hline $3 b$ & $305,324,349$ & 369,390 & 0.31 & 398 & 0.11 & $(0.18,0.11)$ & 3.33 & 0.99 & 5.95 & 2.62 \\
\hline
\end{tabular}

${ }^{\text {a }}$ Measured in $\mathrm{CH}_{2} \mathrm{Cl}_{2}$ at $10 \mu \mathrm{M}$. Quantum yield measurements (Ф) were done after excitation at $300 \mathrm{~nm}$ using POPOP as the standard reference (1,4-bis(5-phenyl-2-oxazolyl)benzene). ${ }^{b}$ Measured in thin films on quartz substrates. ${ }^{c}$ Optical gap energy. ${ }^{d}$ Onset oxidation potential determined from cyclic voltammetry. ${ }^{\mathrm{e}} \mathrm{IP}=E_{\text {onset }}{ }^{\text {ox }}-E^{0}\left(\mathrm{Fc} / \mathrm{Fc}^{+}\right)+5.39$. 
a)

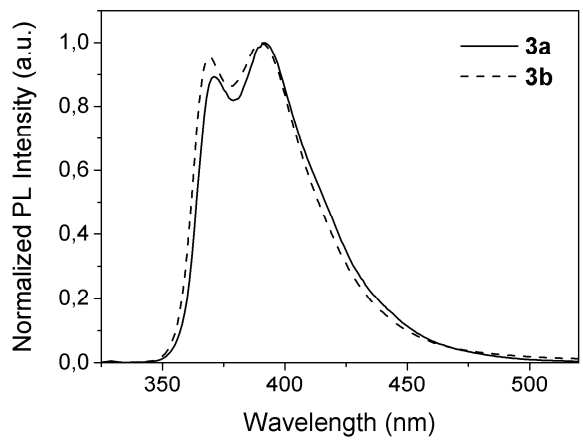

b)

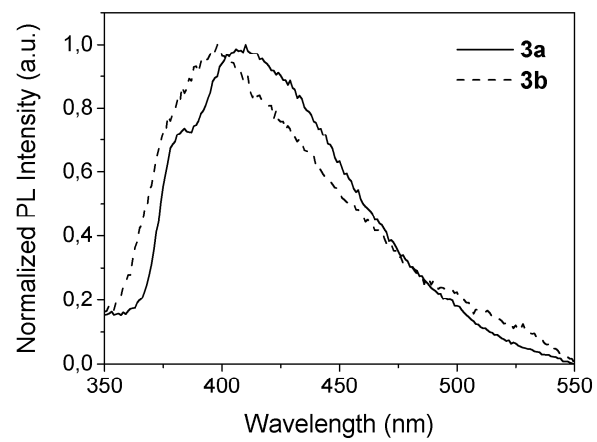

Fig. 1 Photoluminescence spectra of compounds $\mathbf{3 a}$ and $\mathbf{3 b}$ a) in dichloromethane at a concentration of $10 \mu \mathrm{M}$ and $\mathrm{b}$ ) in the solid state.

demonstrated to be more efficient to avoid the quenching of the fluorescence, than the steric hindrance introduced by the 3,5-di-tert-butylphenyl group. It is worth to take into account that the three carbazole units in molecules $\mathbf{3 a}$ and $\mathbf{3 b}$ are linked by a triple bond. When the triple bond is used as a $\pi^{-}$ spacer the Stokes Shift is reduced in comparison to the double bond analog ${ }^{9}$ keeping the fluorescence emission wavelength in the blue zone. It is interesting to highlight that both compounds present a CIE y coordinate in the range of the deep blue region emission (CIE y coordinate lower than 0.1).

In order to increase efficiency in OLED devices it is a good strategy to design luminescent dyes, not only with high quantum yields in the solid state at the selected wavelengths but also with high charge carrier mobilities to favour the whole electroluminescence process.

\section{Electrochemical properties}

Electrochemical properties of compounds $\mathbf{3 a}$ and $\mathbf{3 b}$ were analysed. Cyclic voltammetry (CV) for both compounds were performed in dichloromethane containing 0.1 M TBAP as the supporting electrolyte. Both compounds showed one irreversible oxidation process by cyclic voltammetry (Fig. S17† in the ESI), being both stable to the reduction process. Table 1 collects the electrochemical characteristics. High ionization potential (IP) values $(\sim 5.9 \mathrm{eV})$, estimated from oxidation onset potentials by cyclic voltammetry, and high optical gap energy values $(\sim 3.3 \mathrm{eV})$, estimated in combination with UV-visible spectra, were obtained for compound $\mathbf{3 a}$ and $\mathbf{3 b}$, which are indicative of potential hole conduction properties. The substitution of the nitrogen atoms of the carbazole moieties has a slight influence on the ionization potential values, being the ionization potential of the $\mathrm{N}$-aryl derivative $\mathbf{3 b}$ slightly higher.

The nature of the $\pi$-spacer between two carbazole units influences the electron affinity (EA) values. ${ }^{9}$ Lower EA values were obtained for bicarbazole derivatives bonded by two consecutive triple bonds, instead of by only one double bond or one triple bond. Compounds $\mathbf{3} \mathbf{a}$ and $\mathbf{3} \mathbf{b}$, which consist on three carbazole units with a triple bond as a $\pi$-spacer intercalated between them, present low EA values which potentially facilitates electron injection into the active layer.

\section{Charge transport properties}

Ionization potential (IP), which characterizes the electron releasing work under illumination, was also determined in the solid state for both $\mathbf{3 a}$ and $\mathbf{3 b}$ compounds by the photoemission in air method. Photoemission spectra of the amorphous films of both compounds in air are shown in Fig. 2a. IP values for compounds $\mathbf{3 a}$ and $\mathbf{3 b}$ are 5.33 and $5.44 \mathrm{eV}$, respectively, close to that of indium tin oxide $(4.8 \mathrm{eV})$. The nature of the $\mathrm{N}$-substituents of the carbazole core has only a slight influence on the ionization potential values. This observation is in agreement with previous reports where it was found that the modification of the substitution patterns of the carbazole moiety practically does not affect the ionization energy values. ${ }^{10}$ It should be taken into account that from the electrochemical properties, the IP values of compounds 3a and 3b (Table 1) were determined in solution, whereas in the photoemission in air technique the IP is referred to solid thinfilms. This slightly difference in IP values obtained from the two different techniques has been previously reported. ${ }^{11}$

a)

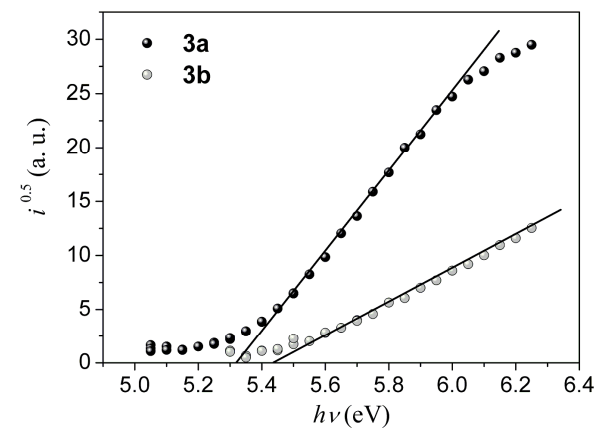

b)

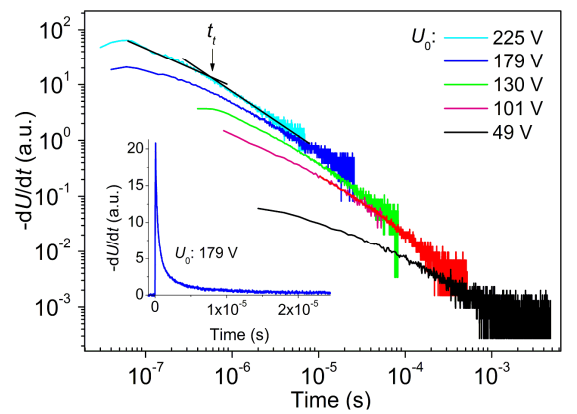

Fig. 2 a) Photoemission spectra of the amorphous films of compounds $3 a$ and $\mathbf{3 b}$ measured in air at $25^{\circ} \mathrm{C}$. b) XTOF transients for compound $3 \mathbf{a}$ measured at $25^{\circ} \mathrm{C}$. Insert shows one transient curve in linear plot. 

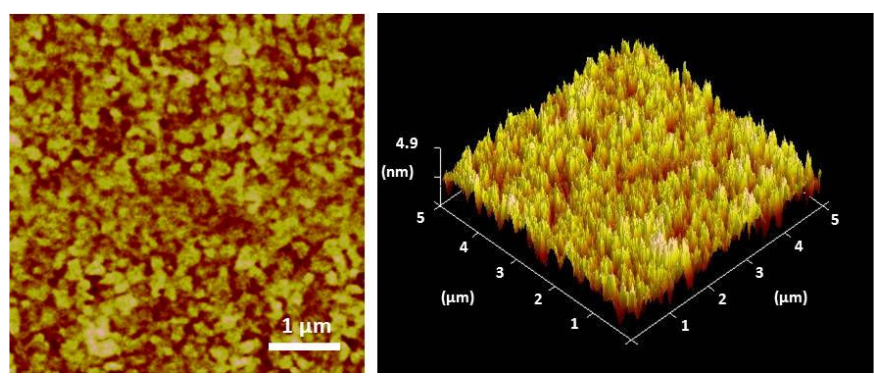

Fig. 3 AFM image of a solution-processed 3 a based thin-film from two different points of view $\left(5 \times 5 \mu \mathrm{m}^{2}\right)$.

For the estimation of hole transport properties, amorphous layers of the synthesized materials were prepared and subjected to the Xerographic Time-of-Flight (XTOF) measurements. Representative XTOF transients for hole transport of compound $\mathbf{3 a}$ are displayed in Figure 3a, showing a dispersive pattern. The attempts to estimate the hole mobility for compound $\mathbf{3 b}$ were unsuccessful, due to the much more dispersive mobility registered for that compound.

The hole-transit times $\left(t_{\mathrm{t}}\right)$ of $\mathbf{3 a}$ were established from intersection points of two asymptotes from the doublelogarithmic plots (Fig. 2b). The dependency of hole drift mobilities on the square root of the electric field for compound $\mathbf{3 a}$ is represented in Fig. $\mathrm{S}^{+} \mathbf{t}^{+}$in the ESI. Compound 3a showed a zero field hole drift mobility $\left(\mu_{0}\right)$ of $2.6 \times 10^{-7}$ $\mathrm{cm}^{2} / \mathrm{Vs}$ and a field dependence parameter $(\alpha)$ of $\sim 0.0087$ $(\mathrm{cm} / \mathrm{V})^{1 / 2}$. Compound 3a showed a hole charge mobility of 2.8 $\times 10^{-4} \mathrm{~cm}^{2} / \mathrm{Vs}$ at a electric field of $6.4 \times 10^{5} \mathrm{~V} / \mathrm{cm}$, which is relatively high and useful for practical applications.

\section{Organic Light-Emitting Diodes}

The optical and electrochemical properties of compound 3a, the high quantum yield in the solid state, together with the suitable blue $\mathrm{CIE}$ coordinates and hole mobility values confer on $3 a$ the sought characteristics for an efficient luminescent dye in the deep blue emission range. On the other hand, film morphology of the emitting layer strongly influences the performance of the organic devices. Tapping mode Atomic Force Microscopy (AFM) was performed in order to characterize the morphology of the thin-film based on
Table 2 Data of best OLED devices based on compound 3a.

\begin{tabular}{cccccc}
\hline device & solvent $^{\mathbf{a}}$ & $\begin{array}{c}\mathbf{d} \\
(\mathbf{n m})\end{array}$ & $\begin{array}{c}\boldsymbol{V}_{\mathbf{t}} \\
\mathbf{( V )}^{\mathbf{c}}\end{array}$ & $\begin{array}{c}\boldsymbol{L}_{\max } \\
\left(\mathbf{c d} / \mathbf{m}^{\mathbf{2}}\right)^{\mathbf{d}}\end{array}$ & $\begin{array}{c}\boldsymbol{\eta}_{\mathbf{c}} \\
(\mathbf{c d} / \mathbf{A})^{\mathbf{e}}\end{array}$ \\
\hline $\mathbf{1}$ & $\mathrm{CB}$ & 25 & 2.80 & 35.59 & 0.08 \\
$\mathbf{2}$ & $\mathrm{CB}$ & 30 & 2.68 & 37.52 & 0.09 \\
$\mathbf{3}$ & $\mathrm{CB}$ & 40 & 2.88 & 40.98 & 0.09 \\
$\mathbf{4}$ & $\mathrm{CB}$ & 50 & 3.23 & 39.46 & 0.17 \\
$\mathbf{5}$ & $\mathrm{CB}$ & 55 & 3.62 & 33.49 & 0.05 \\
$\mathbf{6}$ & $\mathrm{DCM}$ & 25 & 2.61 & 24.75 & 0.03 \\
$\mathbf{7}$ & $\mathrm{THF}$ & 25 & 2.62 & 26.47 & 0.03 \\
\hline
\end{tabular}

Average values are reported in Table S1 + in the ESI. ${ }^{\text {a }}$ Solvent used for preparing the $\mathbf{3 a}$ based layer by spin-coating (CB: chlorobenzene, DCM: dichloromethane, THF: tetrahydrofuran). ${ }^{b}$ Thickness of the $\mathbf{3 a}$ based layer measured with a profilometer. ${ }^{\mathrm{c}}$ Turn-on voltage defined as voltage corresponding to a luminance of $0.1 \mathrm{~cd} / \mathrm{m}^{2}$. ${ }^{\mathrm{d}}$ Maximum luminance. ${ }^{e}$ Maximum current efficiency.

compound 3a (Fig. 3). $25 \mathrm{~nm}$ thick films were prepared by spin casting of a chlorobenzene solution of compound $\mathbf{3 a}$ on a PEDOT:PSS treated ITO substrate. AFM images show homogeneous and continuous thin-films of compound 3a prepared by solution processing with a root-mean-square (rms) roughness of $\sim 1.46 \mathrm{~nm}$, showing appropriate morphology layer characteristics.

Consequently, the molecule $3 \mathbf{a}$ has been tested as emissive layer in non-doped single-layer light emitting diodes. The here presented OLED configuration consisted on ITO/PEDOT:PSS (25 $\mathrm{nm}) / 3 a(25-55 \mathrm{~nm}) / \mathrm{TPBi}(10 \mathrm{~nm}) / \mathrm{LiF}(1 \mathrm{~nm}) / \mathrm{Al}(100 \mathrm{~nm})$ (Fig. 4a). In order to optimize the performance of the devices different thicknesses, from 25 to $55 \mathrm{~nm}$, of the 3 a layer were prepared from chlorobenzene solution by spin coating. The performance characteristics of the different devices are summarized in Fig. $4 \mathrm{~b}$ and $4 \mathrm{c}$ and Table 2. Deposition of the emissive layer of compound 3 a was also tested from different solvent solutions, such as dichloromethane and tetrahydrofuran.

All the devices present competitive turn-on voltages between 2.6 and $3.6 \mathrm{~V}$ indicating small injection barriers from the transporting layers in the device. The luminance increases upon voltage application, reaching the maximum values below $5 \mathrm{~V}$. The maximum luminance values are dependent on the a)

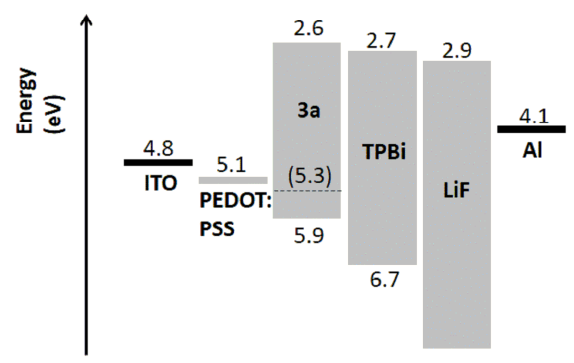

b)

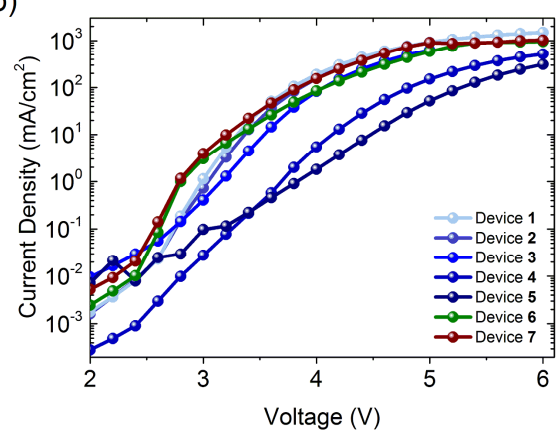

c)

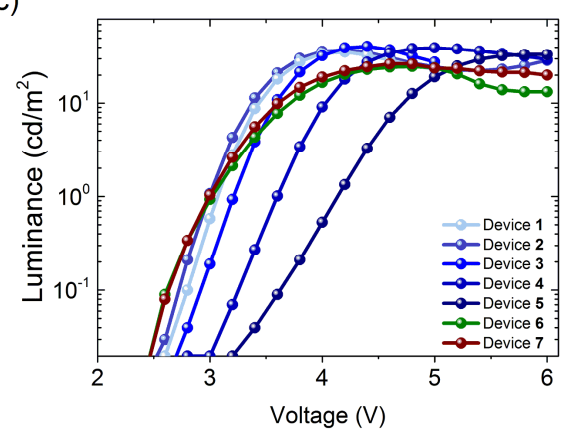

Fig. 4 a) Energetic scheme of the different components of the device structure used in this study. The dashed line in $\mathbf{3 a}$ component indicates the ionization potential obtained from the photo-emission in air technique. This value is displayed in parentheses. b) Current density-voltage and c) luminance-voltage characteristics of the devices summarized in Table 2. 
thickness of the active layer, reaching the optimum ratio between luminance and current efficiency at $50 \mathrm{~nm}$. Further increase of the thickness leads to a decrease of the maximum luminance and efficiency together with an increase of the turnon voltage, pointing to growing unbalance of the charge transport in the device. On the other hand, the devices prepared from DCM and THF solutions show poorer performances suggesting the influence of the solvent on the final morphology of the active layer.

\section{Conclusions}

Tricarbazoles $\mathbf{3} \mathbf{a}$ and $\mathbf{3} \mathbf{b}$ show the sought deep blue emission in the solid state, as a result of linking the three carbazole units by a triple bond as a $\pi$-spacer. In addition, alkylation of the nitrogen positions of the lateral carbazole units with 2ethylhexyl chains transfers the quantum yield determined in solution to that in the solid state without significant reduction. Solution processed non-doped OLED devices from compound 3a demonstrates its potential as a blue deep emitter in nondoped devices, reaching luminances of up to $40 \mathrm{~cd} / \mathrm{m}^{2}$ and current efficiency of $0.2 \mathrm{~cd} / \mathrm{A}$.

\section{Experimental}

\section{Materials}

All chemicals were of commercial grade and used as received. All solvents were dried and degassed by standard methods. Tetrahydrofuran was distilled from sodium/benzophenone. The starting materials 3-iodo-9H-carbazole (MIC) and 3,6diiodo-9H-carbazole (DIC) were obtained according to the procedures described in the literature. ${ }^{8}$ 3,6-diethynyl- $9 H$ carbazole was synthesized from 3,6-diiodo-9H-carbazole according to reported procedures. ${ }^{6}$

\section{Synthesis of 9-(2-ethylhexyl)-3-iodo-9H-carbazole (1)}

$1.20 \mathrm{~g}(4.09 \mathrm{mmol})$ of 3-iodo- $9 \mathrm{H}$-carbazole dissolved in $10 \mathrm{ml}$ of DMF, $2.37 \mathrm{~g}(12.27 \mathrm{mmol}, 2.18 \mathrm{~mL})$ of 2-ethylhexyl bromide, $0.92 \mathrm{~g}(16.36 \mathrm{mmol})$ of $\mathrm{KOH}$ and $0.58 \mathrm{~g}(4.09 \mathrm{mmol})$ of anhydrous $\mathrm{Na}_{2} \mathrm{SO}_{4}$ were stirred at room temperature for 10 min. After termination of the reaction, the reaction mixture was diluted with water and the product was extracted with ethyl acetate. The organic layer was washed thoroughly with water until the aqueous layer was neutral, dried over anhydrous $\mathrm{MgSO}_{4}$, filtered off and the solvent was distilled off under reduced pressure. The crude was purified by flash column chromatography using hexane as the eluent. The yield was $1.30 \mathrm{~g}(80 \%) .{ }^{1} \mathrm{H}$ NMR (400 MHz, $d_{6}$-acetone) $\delta$ (ppm): 8.50 $(\mathrm{d}, J=1.7 \mathrm{~Hz}, 1 \mathrm{H}), 8.18(\mathrm{~d}, J=7.8 \mathrm{~Hz}, 1 \mathrm{H}), 7.72\left(\mathrm{dd}, J_{1}=8.6 \mathrm{~Hz}\right.$, $\left.J_{2}=1.7 \mathrm{~Hz}, 1 \mathrm{H}\right), 7.56(\mathrm{~d}, J=8.3 \mathrm{~Hz}, 1 \mathrm{H}), 7.51-7.47(\mathrm{~m}, 1 \mathrm{H}), 7.43$ $(\mathrm{d}, J=8.6 \mathrm{~Hz}, 1 \mathrm{H}), 7.25-7.21(\mathrm{~m}, 1 \mathrm{H}), 4.30(\mathrm{~d}, J=7.6 \mathrm{~Hz}, 2 \mathrm{H})$, 2.14-2.07 (m, $1 \mathrm{H}), 1.46-1.17(\mathrm{~m}, 8 \mathrm{H}), 0.91(\mathrm{t}, J=7.5 \mathrm{~Hz}, 3 \mathrm{H})$, $0.81(t, J=7.2 \mathrm{~Hz}, 3 \mathrm{H})$.

\section{Synthesis of 9-(3,5-di-tert-butylphenyl)-3-iodo-9H-carbazole (2)}

$4.50 \mathrm{~g}(15.35 \mathrm{mmol})$ of 3-iodo-9H-carbazole, $12.40 \mathrm{~g}(46.05$ $\mathrm{mmol}$ ) of 1-bromo-3,5-di-tert-butylbenzene, $4.24 \mathrm{~g}$ (30.70 mmol) of anhydrous $\mathrm{K}_{2} \mathrm{CO}_{3}$ and $0.13 \mathrm{~g}$ (1.99 mmol) of $\mathrm{Cu}$ powder was refluxed in $35 \mathrm{ml}$ of anhydrous DMF under nitrogen atmosphere for $72 \mathrm{~h}$. After, the reaction mixture was filtered through Celite and diluted with water. The product was extracted with ethyl acetate and the organic layer was washed thoroughly with water until the aqueous layer was neutral. The organic extract was dried over anhydrous $\mathrm{MgSO}_{4}$, filtered off and the solvent was distilled off under reduced pressure. The residue was purified by column chromatography using hexane as the eluent. The yield was $1.51 \mathrm{~g}(21 \%) .{ }^{1} \mathrm{H}$ NMR (400 MHz, $d_{6}$-acetone) $\delta$ (ppm): $8.59(\mathrm{~d}, J=1.7 \mathrm{~Hz}, 1 \mathrm{H}), 8.27(\mathrm{~d}, J=7.8 \mathrm{~Hz}$, $1 \mathrm{H}), 7.71(\mathrm{dd}, J=8.6 \mathrm{~Hz}, J=1.7 \mathrm{~Hz}, 1 \mathrm{H}), 7.67(\mathrm{t}, J=1.7 \mathrm{~Hz}, 1 \mathrm{H})$, 7.50-7.45 (m, 3H), $7.41(\mathrm{~d}, J=8.2 \mathrm{~Hz}, 1 \mathrm{H}), 7.33-7.29(\mathrm{~m}, 1 \mathrm{H})$, $7.26(\mathrm{~d}, J=8.6 \mathrm{~Hz}, 1 \mathrm{H}), 1.42(\mathrm{~s}, 18 \mathrm{H}) .{ }^{13} \mathrm{C} \mathrm{NMR}\left(100 \mathrm{MHz}, d_{6^{-}}\right.$ acetone) $\delta$ (ppm): 153.8, 141.8, 141.0, 137.3, 135.1, 130.0, $127.8,126.7,122.8,122.6,121.8,121.5,121.2$, 113.0, 110.8, 82.6, 35.8, 31.7. HRMS (ESI-MS) $(m / z)$ : calcd for $\mathrm{C}_{26} \mathrm{H}_{29} \mathrm{IN}(\mathrm{M}+$ $H)^{+}$482.1339, found: 482.1348 .

\section{Synthesis of 3,6-bis[2-(9-(2-ethylhexyl)-9H-carbazol-3-yl)ethynyl]- $9 \mathrm{H}$-carbazole (3a)}

$1.19 \mathrm{~g}$ (2.94 mmol) of 9-(2-ethylhexyl)-3-iodo-9H-carbazole (1), $0.035 \mathrm{~g}(0.05 \mathrm{mmol})$ of $\mathrm{Pd}\left(\mathrm{PPh}_{3}\right)_{2} \mathrm{Cl}_{2}$ and $0.025 \mathrm{~g}(0.13 \mathrm{mmol})$ of Cul were dissolved in $10 \mathrm{~mL}$ of anhydrous THF under nitrogen atmosphere. Then, $0.35 \mathrm{~g}(3.43 \mathrm{mmol}, 0.48 \mathrm{~mL})$ of triethylamine and a solution of 3,6-diethynyl-9H-carbazole $(0.21$ $\mathrm{g}, 0.98 \mathrm{mmol}$ ) in THF were added and stirred at room temperature for $10 \mathrm{~min}$. After termination of the reaction, 3a was isolated according to the procedure described for $\mathbf{2}$, using a mixture of hexane and ethyl acetate $(9: 1 \mathrm{v} / \mathrm{v})$ as the eluent. The yield was $0.23 \mathrm{~g}$ (31\%). ${ }^{1} \mathrm{H}$ NMR (400 MHz, $d_{6}$-acetone) $\delta$ (ppm): $10.74(\mathrm{~s}, 1 \mathrm{H}, \mathrm{NH}), 8.46(\mathrm{~s}, 2 \mathrm{H}), 8.39(\mathrm{~d}, J=0.8 \mathrm{~Hz}, 2 \mathrm{H})$, $8.25(\mathrm{~d}, J=7.9 \mathrm{~Hz}, 2 \mathrm{H}), 7.69-7.58(\mathrm{~m}, 10 \mathrm{H}), 7.53-7.48(\mathrm{~m}, 2 \mathrm{H})$, $7.29-7.24(\mathrm{~m}, 2 \mathrm{H}), 4.35(\mathrm{~d}, J=7.6 \mathrm{~Hz}, 4 \mathrm{H}), 2.18-2.10(\mathrm{~m}, 2 \mathrm{H})$, 1.50-1.19 (m, 16H), $0.94(\mathrm{t}, J=7.4 \mathrm{~Hz}, 6 \mathrm{H}), 0.83(\mathrm{t}, J=7.2 \mathrm{~Hz}$, $6 \mathrm{H}) .{ }^{13} \mathrm{C} \mathrm{NMR}\left(100 \mathrm{MHz}, \mathrm{CDCl}_{3}\right) \delta$ (ppm): 141.4, 140.6, 139.3, $130.0,129.3,126.1,124.1,124.0,123.3,123.0,122.6,120.6$, $119.4,115.4,113.8,110.9,109.3,109.2,89.3,88.6,47.7,39.5$, $31.2,28.9,24.6,23.2,14.2$, 11.1. HRMS (ESI-MS) ( $\mathrm{m} / \mathrm{z})$ : calcd for $\mathrm{C}_{56} \mathrm{H}_{56} \mathrm{~N}_{3}(\mathrm{M}+\mathrm{H})^{+} 770.4469$, found: 770.4437 .

\section{Synthesis of 3,6-bis[2-(9-(3,5-di-tert-butylphenyl)-9H-carbazol-3- yl)ethynyl]-9H-carbazole (3b)}

Method A. 3b was prepared and isolated according to the procedure described for $3 \mathrm{a}$, using $0.11 \mathrm{~g}(0.51 \mathrm{mmol})$ of 3,6diethynyl-9H-carbazole, $0.74 \mathrm{~g}(1.53 \mathrm{mmol})$ of $2,0.018 \mathrm{~g}(0.026$ $\mathrm{mmol})$ of $\mathrm{Pd}\left(\mathrm{PPh}_{3}\right)_{2} \mathrm{Cl}_{2}, 0.013 \mathrm{~g}(0.07 \mathrm{mmol})$ of $\mathrm{Cul}$ and $0.18 \mathrm{~g}$ $(1.78 \mathrm{mmol}, 0.25 \mathrm{~mL})$ of triethylamine (TEA). The product was purified using a mixture of hexane and tetrahydrofuran (9:1 $\mathrm{v} / \mathrm{v}$ ) as the eluent. The yield was $0.07 \mathrm{~g}(15 \%)$.

Method B. 3b was prepared and isolated according to the procedure described for $3 \mathrm{a}$, using $0.73 \mathrm{~g}(1.92 \mathrm{mmol})$ of $5,0.27$ $\mathrm{g}(0.64 \mathrm{mmol})$ of 3,6-diiodo-9H-carbazole $0.021 \mathrm{~g}(0.03 \mathrm{mmol})$ 
of $\mathrm{Pd}\left(\mathrm{PPh}_{3}\right)_{2} \mathrm{Cl}_{2}, 0.015 \mathrm{~g}(0.08 \mathrm{mmol})$ of $\mathrm{Cul}$ and $0.23 \mathrm{~g}(2.24$ $\mathrm{mmol}, 0.32 \mathrm{~mL}$ ) of triethylamine. The product was purified by flash column chromatography using a mixture of hexane and ethyl acetate $(4: 1 \mathrm{v} / \mathrm{v})$ as the eluent. The yield was $0.14 \mathrm{~g}$ (24\%). ${ }^{1} \mathrm{H}$ NMR (400 MHz, $d_{6}$-acetone) $\delta$ (ppm): $10.76(\mathrm{~s}, 1 \mathrm{H}$, $\mathrm{NH}), 8.48-8.47(\mathrm{~m}, 4 \mathrm{H}), 8.33(\mathrm{~d}, J=7.8 \mathrm{~Hz}, 2 \mathrm{H}), 7.69-7.65(\mathrm{~m}$, $6 \mathrm{H}), 7.61(\mathrm{~d}, J=8.4 \mathrm{~Hz}, 2 \mathrm{H}), 7.50(\mathrm{~d}, J=1.7 \mathrm{~Hz}, 4 \mathrm{H}), 7.49-7.43$ $(\mathrm{m}, 6 \mathrm{H}), 7.36-7.32(\mathrm{~m}, 2 \mathrm{H}), 1.44(\mathrm{~s}, 36 \mathrm{H}) .{ }^{13} \mathrm{C} N M R(100 \mathrm{MHz}$, $d_{6}$-acetone) $\delta(\mathrm{ppm}): 153.8,142.3,141.1,140.9,137.5,130.4$, $130.3,127.5,124.6,124.4,124.3,123.7,123.7,122.6,121.9$, $121.5,121.2,115.9,115.4,112.3,111.0,110.9,89.8,89.4$, 35.8, 31.7. MS (MALDI-TOF) $(\mathrm{m} / \mathrm{z})$ : calcd for $\mathrm{C}_{68} \mathrm{H}_{63} \mathrm{~N}_{3}\left(\mathrm{M}^{+}\right)$ 921.5, found: 921.5 .

\section{Synthesis of 9-(3,5-di-tert-butylphenyl)-3-[2- (trimethylsilyl)ethynyl)]-9H-carbazole (4)}

$1.33 \mathrm{~g}(2.76 \mathrm{mmol})$ of $2,0.10 \mathrm{~g}(0.14 \mathrm{mmol})$ of $\mathrm{Pd}\left(\mathrm{PPh}_{3}\right)_{2} \mathrm{Cl}_{2}$, $0.07 \mathrm{~g}(0.36 \mathrm{mmol})$ of Cul were dissolved in $10 \mathrm{~mL}$ of anhydrous THF under nitrogen atmosphere. Then, $0.98 \mathrm{~g}(9.68$ $\mathrm{mmol}, 1.35 \mathrm{~mL})$ of triethylamine and $0.54 \mathrm{~g}(5.50 \mathrm{mmol}, 0.78$ $\mathrm{mL}$ ) of ethynyltrimethylsilane dissolved in THF were added and stirred at room temperature for $10 \mathrm{~min}$. 4 was purified according to the procedure described for $\mathbf{2}$. The yield was 1.23 g (98\%). ${ }^{1} \mathrm{H}$ NMR (400 MHz, $d_{6}$-acetone) $\delta(\mathrm{ppm}): 8.35$ (d, $J=$ $1.6 \mathrm{~Hz}, 1 \mathrm{H}), 8.30(\mathrm{~d}, J=7.7 \mathrm{~Hz}, 1 \mathrm{H}), 7.67(\mathrm{t}, J=1.8 \mathrm{~Hz}, 1 \mathrm{H}), 7.52$ (dd, $\left.J_{1}=8.5 \mathrm{~Hz}, J_{2}=1.6 \mathrm{~Hz}, 1 \mathrm{H}\right), 7.49-7.45(\mathrm{~m}, 3 \mathrm{H}), 7.41(\mathrm{~d}, J=$ $8.1 \mathrm{~Hz}, 1 \mathrm{H}), 7.38(\mathrm{~d}, J=8.5 \mathrm{~Hz}, 1 \mathrm{H}), 7.34-7.30(\mathrm{~m}, 1 \mathrm{H}), 1.42(\mathrm{~s}$, $18 \mathrm{H}), 0.27(\mathrm{~s}, 9 \mathrm{H}) .{ }^{13} \mathrm{C} \mathrm{NMR}\left(100 \mathrm{MHz}, d_{6}\right.$-acetone) $\delta$ (ppm): $153.8,142.3,141.4,137.3,130.6,127.6,125.0,124.1,123.6$, 122.6, 121.8, 121.5, 121.3, 115.1, 110.9, 110.8, 107.4, 92.2, $35.8,31.7,0.2$. HRMS (ESI-MS) $(\mathrm{m} / \mathrm{z})$ : calcd for $\mathrm{C}_{31} \mathrm{H}_{38} \mathrm{NSi}(\mathrm{M}+$ H) ${ }^{+} 452.2768$, found: 452.2759 .

\section{Synthesis of 9-(3,5-di-tert-butylphenyl)-3-ethynyl-9H-carbazole (5)}

$1.2 \mathrm{~g}(2.66 \mathrm{mmol})$ of 4 and $1.84 \mathrm{~g}(13.31 \mathrm{mmol})$ of anhydrous $\mathrm{K}_{2} \mathrm{CO}_{3}$ were dissolved in $180 \mathrm{~mL}$ of methanol. The reaction mixture was stirred at room temperature for $24 \mathrm{~h}$. After termination of the reaction, the solvent was distilled off under reduced pressure and the product was purified according to the procedure described for 2 . The yield was $0.81 \mathrm{~g}(80 \%) .{ }^{1} \mathrm{H}$ NMR (400 MHz, $d_{6}$-acetone) $\delta(\mathrm{ppm}): 8.38(\mathrm{~d}, J=1.6 \mathrm{~Hz}, 1 \mathrm{H})$, $8.28(\mathrm{~d}, J=7.8 \mathrm{~Hz}, 1 \mathrm{H}), 7.67(\mathrm{t}, J=1.8 \mathrm{~Hz}, 1 \mathrm{H}), 7.55$ (dd, $J_{1}=8.5$ $\left.\mathrm{Hz}, J_{2}=1.6 \mathrm{~Hz}, 1 \mathrm{H}\right), 7.49-7.45(\mathrm{~m}, 3 \mathrm{H}), 7.42(\mathrm{~d}, J=8.3 \mathrm{~Hz}, 1 \mathrm{H})$, $7.39(\mathrm{~d}, J=8.5 \mathrm{~Hz}, 1 \mathrm{H}), 7.34-7.30(\mathrm{~m}, 1 \mathrm{H}), 3.57(\mathrm{~s}, 1 \mathrm{H}), 1.42(\mathrm{~s}$, 18H). ${ }^{13} \mathrm{C}$ NMR (100 MHz, $d_{6}$-acetone) $\delta$ (ppm): 153.3, 141.7, $140.9,136.8,130.3,127.3,124.9,123.7,123.0,122.2,121.4$, $121.3,121.0,113.9,110.6,110.5,85.0,78.0,35.4,31.4$. HRMS (ESI-MS) $(m / z)$ : calcd for $\mathrm{C}_{28} \mathrm{H}_{30} \mathrm{~N}(\mathrm{M}+\mathrm{H})^{+} 380.2373$, found: 380.2363 .

\section{Instrumentation and methods}

Silica gel (grade 62, 60-200 mesh, $150 \AA$, Aldrich) was used for flash column chromatography. ${ }^{1} \mathrm{H}$ NMR $(400 \mathrm{MHz})$ and ${ }^{13} \mathrm{C}$ NMR $(100 \mathrm{MHz})$ were collected on a Varian Mercury spectrometer. MALDI-TOF was performed on an Applied
Biosystems MDS SCIEX 4800 equipment. High-resolution mass spectroscopy (HR-MS) was performed on a LC/MSD-TOF Agilent Technologies apparatus by means of the electrospray (ESI-MS) technique. UV-vis spectra were registered in a Varian Cary UV-Vis-NIR 500E spectrophotometer. Emission spectra in solution were recorded in a PTI fluorimeter equipped with a 220B lamp power supply, a 815 photomultiplier detection system and a Felix 32 software after excitation at $300 \mathrm{~nm}$ and at a concentration of $10 \mu \mathrm{M}$ in dichloromethane. Photophysical measurements in the solid state were done on films deposited from a $1 \mathrm{mM}$ dichloromethane solution by spin coating at $1500 \mathrm{rpm}$ for $20 \mathrm{~s}$ and at $3500 \mathrm{rpm}$ for $10 \mathrm{~s}$ followed by $5 \mathrm{~min}$ of thermal annealing at $50{ }^{\circ} \mathrm{C}$. Quantum yield measurements in solution and in the solid state were determined after excitation at $300 \mathrm{~nm}$ using optically-matched solutions of 1,4-bis(5-phenyl-2-oxazolyl)benzene (POPOP) as the standard ( $\phi=0.93$ in cyclohexane) following the reported methods. ${ }^{12}$ Colour rendering indexes were calculated after excitation at $310 \mathrm{~nm}$. Cyclic voltammograms were carried out in a microcomputer-controlled potentiostat/galvanostat Autolab with PGSTAT30 equipment and GPES software. A cylindrical three-electrode cell was used. The reference electrode was a Metrohm $\mathrm{Ag} / \mathrm{AgCl} / \mathrm{KCl}(3 \mathrm{M})$ mounted in a Luggin capillary containing a $0.1 \mathrm{M}$ solution of tetrabutylammonium perchlorate (TBAP) in dichloromethane. The counter and working electrodes were a platinum spiral and a platinum wire, respectively. All voltammetric curves were recorded under quiescent conditions, at a scan rate of $100 \mathrm{mV} / \mathrm{s}$ and under argon atmosphere. All solutions were prepared in dichloromethane $(1 \mathrm{mM})$. TBAP (Aldrich, electrochemical grade) was used as the supporting electrolyte. The ionization potential (IP) values were estimated from the onset of the first oxidation peak as $I P=E_{\text {onset }}^{\text {ox }}-E^{0}\left(\mathrm{Fc} / \mathrm{Fc}^{+}\right)+$ 5.39, where $E^{0}\left(\mathrm{Fc} / \mathrm{Fc}^{+}\right)=+0.43 \mathrm{~V}$ vs $\mathrm{Ag} / \mathrm{AgCl} / \mathrm{KCl}(3 \mathrm{M})$ and where $5.39 \mathrm{eV}$ corresponds to the formal potential of the $\mathrm{Fc} / \mathrm{Fc}^{+}$redox couple in the Fermi scale. ${ }^{13}$ The electron affinity values (EA) were calculated as EA $=I P-E_{\text {gap }}$. The optical gap energy $\left(E_{\text {gap }}\right)$ was estimated from $\lambda_{\text {onset }}$ of the absorption spectra. Ionization potential was measured by the photoemission in air method. ${ }^{14}$ The samples for the hole mobility measurements were prepared by spin-coating the solutions of the synthesized compounds on the polyester films with conductive Al layer. The layer thickness was in the range 1.8-6 $\mu \mathrm{m}$. The hole drift mobility was measured by the XTOF technique. ${ }^{15}$ Positive corona charging created electric field inside the TM layer. Charge carriers were generated at the layer surface by illumination with pulses of $\mathrm{N}_{2}$ laser (pulse duration was $2 \mathrm{~ns}$, wavelength $337 \mathrm{~nm}$ ). The layer surface potential decrease as a result of pulse illumination was up to $1-5 \%$ of the initial potential before illumination. The capacitance probe that was connected to the wide frequency band electrometer measured the rate of the surface potential decrease, $\mathrm{dU} / \mathrm{dt}$. The transit time $t_{\mathrm{t}}$ was determined by the kink on the curve of the $\mathrm{dU} / \mathrm{dt}$ transient in the log-log scale. The drift mobility was calculated by the formula $\mu=d^{2} / U_{0} t_{t}$, where $d$ is the layer thickness and $U_{0}$ is the surface potential at the moment of illumination. AFM experiments were 
conducted using an AFM Multimode 8 system attached to a Nanoscope $V$ electronic unit (Bruker).

\section{OLED device fabrication and measurements}

The substrates were cleaned by ultrasonic treatment in acetone and isopropyl alcohol and subsequently dried by a nitrogen blow. After that, their surfaces were processed with ozone treatment for 30 minutes. Subsequently, PEDOT:PSS (Clevios PV P Al4083 from H.C. Starck, filtered at $0.45 \mu \mathrm{m}$ ) was spin-coated at $4500 \mathrm{rpm}$ (thickness around $25 \mathrm{~nm}$ ) onto the ITO surface and lately baked at $120^{\circ} \mathrm{C}$ for $20 \mathrm{~min}$. After that, starting from a solution of $10 \mathrm{mg} / \mathrm{mL}$, 3a was spin casted from different solvents on the PEDOT:PSS layer and successively heated at $50{ }^{\circ} \mathrm{C}$ for $5 \mathrm{~min}$. Samples were transferred into a nitrogen filled glovebox where $10 \mathrm{~nm}$ of TPBi, $1 \mathrm{~nm}$ of LiF and $100 \mathrm{~nm}$ of Al were deposited by thermal evaporation on the active layer under high vacuum. The devices were put in a sample holder that protect them from oxygen and moisture and allow contacting them for measuring. The effective area of each cell was $\sim 9 \mathrm{~mm}^{2}$. The current density-voltage and luminance-voltage data were simultaneously acquired by a Keithley 2400 unit (current) and a Konica-Minolta LS-100 (luminance).

\section{Acknowledgements}

Financial support from the Ministerio de Economía y Competitividad (CTQ2012-36074) is gratefully acknowledged. $M R$ is grateful for the grant ADR from Universitat de Barcelona (UB). EP thanks MINECO project CTQ2013-47183 as well as the Severo Ochoa Excellence Accreditation 2014-2018 (SEV-20130319). EP is also grateful to ICIQ and ICREA for economical support. EMF acknowledges MINECO for the project MAT2012-31570 and Ramon y Cajal fellowship (RyC-201006787). V. Gaidelis, Department of the Solid State Electronic, Vilnius University, is thanked for the measurements of ionization potentials.

\section{Notes and references}

1 X. Yang, X. Xu and G. Zhou, J. Mater. Chem. C, 2015, 3, 913.

2 a) L. Wang, Y. Jiang, J. Luo, Y. Zhou, J. Zhou, J. Wang, J. Pei and Y. Cao, Adv. Mater., 2009, 21, 4854. b) J.-H. Jou, J.-R. Tseng, K.-Y. Tseng, W.-B. Wang, Y.-C. Jou, S.-M. Shen, Y.-L. Chen, W.-Y. Hung, S.-Z. Chen, T.-Y. Ding and H.-C. Wang, Organic Electronics, 2012, 13, 2893. c) D. Chercka, S.-J. Yoo, M. Baumgarten, J.-J. Kim and K. Müllen, J. Mater. Chem. C.,
2014, 2, 9083. d) M. Zhu and C. Yang, Chem. Soc. Rev., 2013, 42, 4963. e) X. Tang, Q. Bai, Q. Peng, Y. Gao, J. Li, Y. Liu, L. Yao, P. Lu, B. Yang and Y. Ma, Chem. Mater., 2015, 27, 7050.

3 a) M. Reig, J. Puigdollers and D. Velasco, J. Mater. Chem. C., 2015, 3, 506. b) S. Chen, B. Sun, W. Hong, Z. Yan, H. Aziz, Y. Meng, J. Hollinger, D. S. Seferos and Y. Li, J. Mater. Chem. C., 2014, 2, 1683. c) P.-L. T. Boudreault, S. Wakim, M. L. Tang, Y. Tao, Z. Bao and M. Leclerc, J. Mater. Chem., 2009, 19, 2921. d) N. Drolet, J.-F. Morin, N. Leclerc, S. Wakim, Y. Tao and M. Leclerc, Adv. Funct. Mater., 2005, 15, 1671. e) C. Beginn, J. V. Grazulevicius and P. Strohriegl, Macromol. Chem. Phys., 1994, 195, 2353.

4 a) M. Yu, S. Wang, S. Shao, J. Ding, L. Wang, X. Jing and F. Wang, J. Mater. Chem. C, 2015, 3, 861. b) F. Niu, H. Niu, Y. Liu, J. Lian and P. Zeng, RSC Adv., 2011, 1, 415. c) S. H. Kim, I. Cho, M. K. Sim, S. Park and S. Y. Park, J. Mater. Chem., 2011, 21, 9139. d) S.-L. Lin, L.-H. Chan, R.-H. Lee, M.-Y. Yen, W.-J. Kuo, C.-T. Chen and R.-J. Jeng, Adv. Mater., 2008, 20, 3947.

5 R. Chinchilla and C. Nájera, Chem. Rev., 2007, 107, 874.

6 S. Shanmugaraju, A. K. Bar, K.-W. Chi and P. S. Mukherjee, Organometallics, 2010, 29, 2971.

7 a) V. Vaitkeviciene, S. Grigalevicius, J. V. Grazulevicius, V. Jankauskas and V. G. Syromyatnikov, European Polymer Journal, 2006, 42, 2254. b) A. Tomkeviciene, T. Bartiuk, A. Bucinskas, J. V. Grazulevicius and V. Jankauskas, Reactive \& Functional Polymers, 2011, 71, 796.

8 S. H. Tucker, J. Chem. Soc., 1926, 129, 546. DOI: 10.1039/JR9262900546.

9 S.-I. Kato, H. Noguchi, A. Kobayashi, T. Yoshihara, S. Tobita and Y. Nakamura, J. Org. Chem., 2012, 77, 9120.

10 a) A. Bucinskas, G. Bagdziunas, A. Tomkeviciene, D. Volynyuk, N. Kostiv, D. Gudeika, V. Jankauskas, M. Rutkis and J. V. Grazulevicius, RSC Adv., 2015, 5, 49577. b) A. Tomkeviciene, J. V. Grazulevicius, K. Kazlauskas, A. Gruodis, S. Jursenas, T.H. Ke and C.-C. Wu, J. Phys. Chem. C, 2011, 115, 4887.

11 a) N. A. Kukhta, D. Volyniuk, L. Peciulyte, J. Ostrauskaite, G. Juska and J. V. Grazulevicius, Dyes and Pigments, 2015, 117, 122. b) R. R. Reghu, H. K. Bisoyi, J. V. Grazulevicius, P. Anjukandi, V. Gaidelis and V. Jankauskas. J. Mater. Chem., 2011, 21, 7811.

12 a) G. A. Crosby and J. N. Demas, J. Phys. Chem., 1971, 75, 991. b) J. Stampfl, S. Tasch, G. Leising and U. Scherf, Synt. Met., 1995, 71, 2125.

13 a) C. M. Cardona, W. Li, A. E. Kaifer, D. Stockdale, G. C. Bazan, Adv. Mater., 2011, 23, 2367. b) A. J. Bard, L. R. Faulkner, Electrochemical Methods: Fundamentals and Applications, WILEY-VCH, New York, 2001.

14 a) E. Miyamoto, Y. Yamaguchi, M. Yokoyama, Electrophotography, 1989, 28, 364. b) M. Daskeviciene, V. Getautis, J.V. Grazulevicius, A. Stanisauskaite, J. Antulis, V. Gaidelis, V. Jankauskas and J. Sidaravicius, J. Imaging Sci. Technol., 2002, 46, 467.

15 E. Montrimas, V. Gaidelis and A. Pazera, Lithuanian J. Phys., 1966, 6, 569. 